\title{
ASO Visual Abstract: Data-Driven Respectful Discourse in the Society of Surgical Oncology
}

\author{
Camille L. Stewart, $\mathrm{MD}^{1}$ (1), Susanne G. Warner, $\mathrm{MD}^{2}$, James De Andrade, $\mathrm{MD}^{3}$, Andrew Nguyen, $\mathrm{MD}^{2}$, and \\ Martin Heslin, $\mathrm{MD}^{4}$ \\ ${ }^{1}$ Department of Surgery, Division of Surgical Oncology, University of Colorado School of Medicine, Anschutz Medical \\ Campus, Aurora, CO; ${ }^{2}$ Department of Surgery, City of Hope National Medical Center, Duarte, CA; ${ }^{3}$ Department of \\ Surgery, School of Medicine, University of Iowa, Iowa City, IA; ${ }^{4}$ Department of Surgery, University of South Alabama \\ School of Medicine, Mobile, AL
}

Prior work has suggested unconscious bias in speaker introductions at SSO annual meetings. Surveys show that speakers prefer professional forms of address during introductions. Guidelines for respectful discourse were developed and distributed to 2021 SSO meeting moderators, after which professional introductions increased significantly, helping to create an inclusive environment (https://doi.org/10.1245/s10 434-021-10808-2).

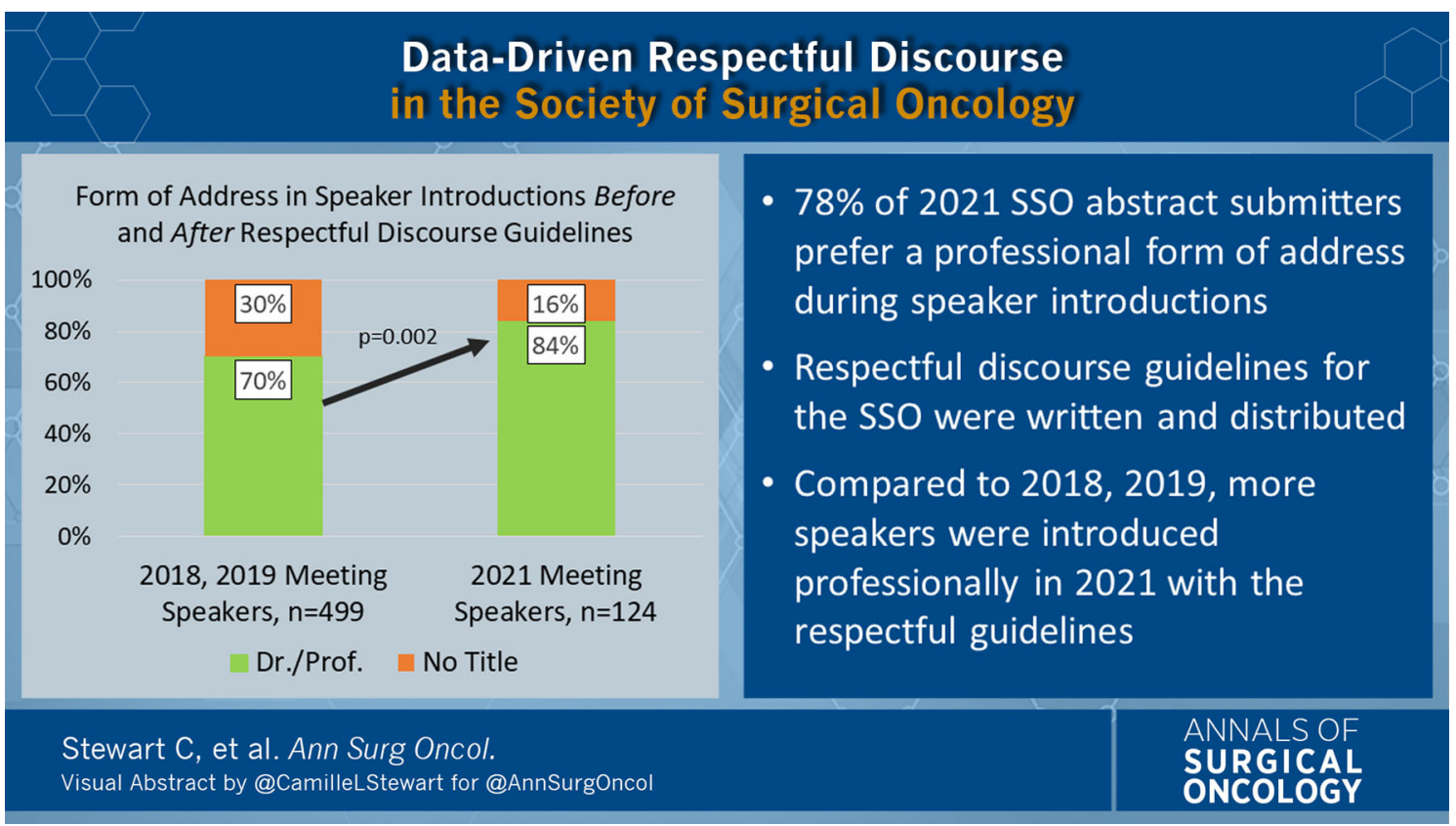

(C) Society of Surgical Oncology 2021

Published Online: 29 October 2021

C. L. Stewart, MD

e-mail: Camille.Stewart@CUAnschutz.edu
FUNDING Martin Heslin-Best Doctors Inc.: electronic consults.

Publisher's Note Springer Nature remains neutral with regard to jurisdictional claims in published maps and institutional affiliations. 